\title{
Beneficial worm allies warn plants of parasite attack belowground and reduce aboveground 1 herbivore preference and performance 2
}

Shokoofeh Kamali ${ }^{1}$, Ali Javadmanesh ${ }^{2}$, Lukasz L Stelinski ${ }^{3}$, Tina Kyndt ${ }^{4}$, Alireza Seifi ${ }^{5}$, Monireh Cheniani $^{6}$, Mohammad Zaki -Aghl ${ }^{1,3}$, Mojtaba Hosseini ${ }^{1}$, Mahyar Heydarpour ${ }^{7}$, Javad Asili $^{8}$, and Javad Karimi ${ }^{9}$

${ }^{1}$ Department of Plant Protection, Faculty of Agriculture, Ferdowsi University of Mashhad

${ }^{2}$ Department of Animal 5 Science, Faculty of Agriculture, Ferdowsi University of Mashhad

${ }^{3}$ Department of Entomology and Nematology

${ }^{4}$ Department of Molecular 7 Biotechnology, Ghent University

${ }^{5}$ Department of Biotechnology and Plant Breeding, Faculty of Agriculture

${ }^{6}$ Department of Biology, Faculty of Science, Ferdowsi University of Mashhad

${ }^{7}$ Department of Anesthesiology, Perioperative and Pain Medicine, Brigham and Women's Hospital, Harvard Medical 10 School

${ }^{8}$ Department of Pharmacognosy, School of Pharmacy, Mashhad University of Medical Sciences

${ }^{9}$ Affiliation not available

October 5, 2021

\section{Hosted file}

MS-Mol. Ecol.-2-1.pdf available at https://authorea.com/users/425486/articles/530992beneficial-worm-allies-warn-plants-of-parasite-attack-belowground-and-reduceaboveground-1-herbivore-preference-and-performance-2 